\title{
Assessing the Binding and Endocytosis Activity of Cellular Receptors Using GFP-Ligand Fusions
}

BioTechniques 29:602-609(September 2000)

\author{
Lali K. Medina-Kauwe, \\ Vivian Leung, Louis Wu and \\ Larry Kedes \\ University of Southern Califor- \\ nia Keck School of Medicine, \\ Los Angeles, CA, USA
}

\section{INTRODUCTION}

Current methods for studying receptor binding and internalization commonly use radioactively labeled ligands or time-consuming fixation protocols that may distort both cells and proteins. We developed two simple nonradioactive assays for characterizing ligand-receptor binding and post-binding activity on unfixed, viable cells using the jellyfish Aequorea victoria green fluorescent protein (GFP) $(6,7,34)$.

Because of its inherent fluorescence, GFP is ideal for experimental assays and detection methods on live cells $(10,11$, $18,22)$. The isolation and cloning of the GFP gene has allowed the production of recombinant protein for biochemical analyses $(8,9,18,24,29)$, and recombinant GFP appears to retain its fluorescence and stability when produced as a fusion protein with foreign sequences. We have constructed recombinant genes encoding GFP fused to ligand proteins to study receptor-ligand interactions. The use of GFP in this capacity allows direct detection of ligand-receptor interactions while avoiding the need for additional biochemical treatments to detect activity, thus shortening and simplifying certain experimental procedures.

One of the ligand proteins that we use in our assays, heregulin- $\alpha$, binds with high affinity to heterodimers of HER2/3 or HER2/4 receptor subunits, which are overexpressed on certain mammary tumor cell lines $(1,3,4,12$, 17,25-27,35). The binding kinetics between heregulin isomers and their target receptors have been well characterized using classical receptor-binding techniques, and the internalization activities of the receptor subunits have been studied $(5,16,19-21,28,30,31)$. Here, we demonstrate that GFP can be used to monitor receptor binding and cellular internalization of the heregulin ligand under real-time conditions, and these activities can be measured using fluorescence-activated cell sorting (FACS).

\section{MATERIALS AND METHODS}

\section{Cell Lines}

The human breast cancer cell line MDA-MB-453 has been adapted to Dulbecco's modified Eagle's medium (DMEM) supplemented with $10 \%$ fetal bovine serum (FBS). HeLa cells are also maintained in the same media. Cells are grown at $37^{\circ} \mathrm{C}$ in the presence of $5 \% \mathrm{CO}_{2}$.

\section{Construction of Plasmids}

Oligonucleotide primers were used to amplify the region encoding the receptor binding domains of heregulin- $\alpha_{1}$ (eHRG) and adenovirus sero-type 5 fiber protein (Knob) by PCR. Restriction sites for cloning were introduced by both sets of primers. Both DNA fragments were cut and ligated into pRSET $^{\mathrm{TM}}$ A plasmids (Invitrogen, Carlsbad, CA, USA) that we modified by incorporating a cDNA encoding GFP into the multiple cloning region. Our GFP fragment was made by PCR amplification of the coding sequence of GFP minus the stop codon from the pEGFP-N1 plasmid (Clontech Laboratories, Palo Alto, CA, USA). Our ligand inserts were cloned just downstream of the GFP region, placing GFP at the amino (N)-terminus of the fusion protein. Expression from our pRSETGFP plasmids produces GFP-eHRG 
and GFP-Knob proteins, respectively. We also constructed plasmids without GFP inserts to produce untagged eHRG and Knob proteins. All proteins were made as an N-terminal histidine-tagged fusion for purification by metal chelate affinity chromatography. The histidine tag was not removed from our proteins.

\section{Protein Production}

Plasmid constructs were transformed into BL21(DE3)pLysS (Novagen, Madison, WI, USA) competent bacteria and grown in LB supplemented with $0.05 \mathrm{mg} / \mathrm{mL}$ ampicillin and 0.034 $\mathrm{mg} / \mathrm{mL}$ chloramphenicol. Transformants were grown to an OD600 of 0.51 and induced with $1 \mathrm{mM}$ isopropyl- $\beta$ D-thiogalactoside (IPTG). After $3 \mathrm{~h}$ incubation, cells were collected and lysed by freeze-thaw in the presence of lysis buffer ( $50 \mathrm{mM}$ sodium phosphate, monobasic, pH 8.0, $300 \mathrm{mM} \mathrm{NaCl}, 60$ mM imidazole, $0.1 \%$ Triton ${ }^{\circledR}$ X-100 and $1 \mathrm{mM}$ PMSF). Lysates were clarified by high-speed centrifugation and supernatants were incubated on ice for 1 $h$ in the presence of Ni-NTA resin (Qiagen, Valencia, CA, USA) pre-equilibrated with wash buffer $(50 \mathrm{mM}$ sodium phosphate, monobasic, $\mathrm{pH} 8.0,500$ $\mathrm{mM} \mathrm{NaCl}, 60 \mathrm{mM}$ imidazole). Slurries were loaded onto polyprep chromatography columns (Bio-Rad Laboratories, Hercules, CA, USA), which were allowed to empty by gravity flow. Columns were washed with $20 \times$ bead volumes of wash buffer; protein was then eluted with elution buffer $(50 \mathrm{mM}$ sodium phosphate, monobasic, $\mathrm{pH} 8.0$, $500 \mathrm{mM} \mathrm{NaCl}, 500 \mathrm{mM}$ imidazole). Salt and imidazole were removed from protein samples by centrifugation in 10000 molecular weight cutoff ultrafiltration columns (Pall Gelman Laboratory, Ann Arbor, MI, USA).

\section{Cell-Binding Assays}

MDA-MB-453 cells maintained in a 24-well dish (about $10^{5}$ cells/well) were detached by treatment with PBS (13.7 $\mathrm{mM} \mathrm{NaCl}, 0.27 \mathrm{mM} \mathrm{KCl}, 0.43 \mathrm{mM}$ sodium phosphate, dibasic, $0.14 \mathrm{mM}$ potassium phosphate, monobasic) supplemented with $2 \mathrm{mM}$ EDTA. Cells were pelleted and washed four times with $1 \times$ PBS supplemented with $0.01 \%$
$\mathrm{Ca}^{2+}$ and $\mathrm{Mg}^{2+}$, then incubated by rocking for $1 \mathrm{~h}$ on ice with protein mixtures in blocking buffer (PBS and 3\% milk) to reduce nonspecific binding. After incubation, cells were washed four times with PBS to remove unbound proteins, resuspended in $0.5 \mathrm{~mL} \mathrm{PBS}$ and assayed by FACS. Competition assays were performed by repeating the protocol outlined for the cell-binding assay, but by co-incubating a non-GFP-tagged competitor with the protein mixtures.

\section{Internalization Assay}

Cells were maintained on dishes, detached, incubated with protein mixes and washed as outlined above in the cell-binding assay. After the final wash, cells were placed at $37^{\circ} \mathrm{C}$ to allow internalization activity. They were collected by centrifugation $(1000 \times g)$ at the indicated time points after warming, resuspended in $0.1 \mathrm{~mL}$ of $2 \mathrm{mg} / \mathrm{mL}$ trypsin, 2 mM EDTA and incubated at $37^{\circ} \mathrm{C}$ for 1 min with agitation to remove cell surface-bound proteins. Trypsinized cells were centrifuged and washed four times with PBS, then resuspended in $0.5 \mathrm{~mL}$ PBS and analyzed by FACS.

\section{FACS}

Samples were counted using a FACScan $^{\mathrm{TM}}$ (Becton Dickinson, Franklin
Lakes, NJ, USA) with a $15 \mathrm{~mW}$ aircooled argon laser set at an excitation wavelength of $488 \mathrm{~nm}$ and recorded with a 530-nm emission filter.

\section{Microscopy}

Cells were viewed using an IMT-2 inverted UV light microscope (Olym pus America, Melville, NY, USA). GFP fluorescence was observed using a FITC filter. Photomicrographs were taken at $40 \times$ magnification using an Olympus SC35 35 mm camera.

\section{RESULTS AND DISCUSSION}

\section{GFP-Ligand Fusion Proteins Produced at High Levels in Bacteria}

We modified two types of ligand to validate our assays and characterize receptor-binding activity. One of these was a 200-amino acid peptide (eHRG) containing an EGF-like motif that, alone, confers binding specificity to HER2-containing receptors $(14,16)$. The version of ligand presented here has successfully directed the cell-specific binding of retroviral vectors when genetically engineered into the viral envelope (13), suggesting that heregulin binding is not impaired when produced as a fusion to foreign sequences. We

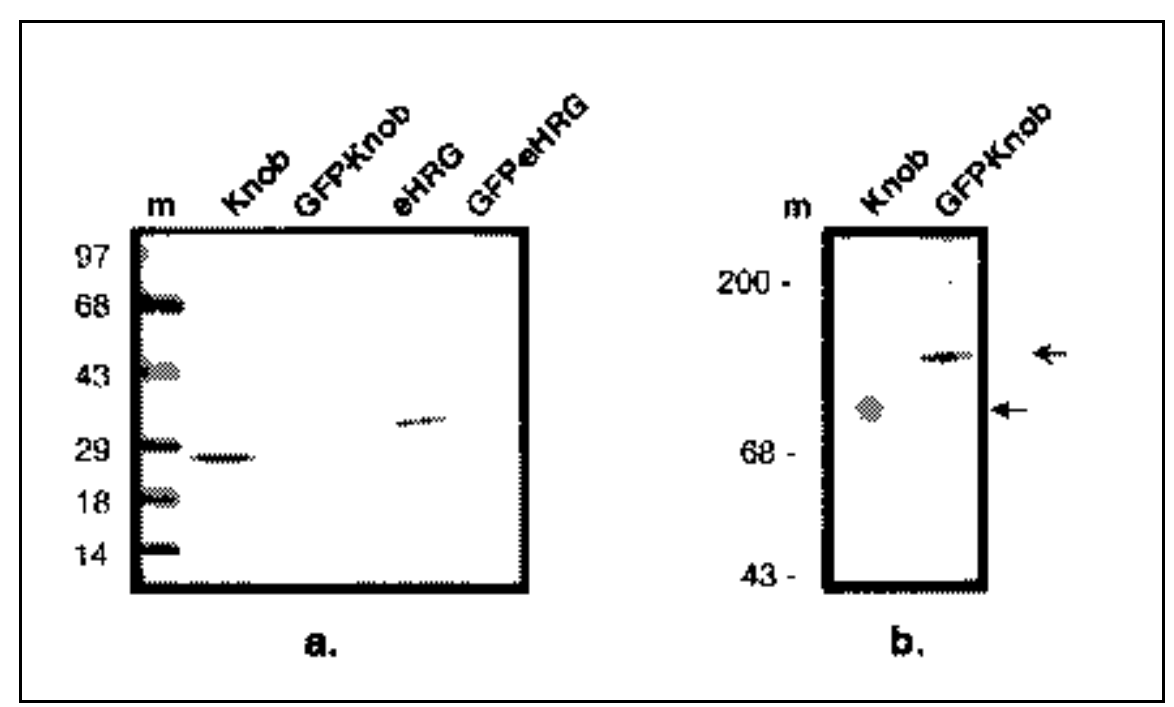

Figure 1. Denaturing and non-denaturing PAGE analysis of recombinant proteins. Sizes of marker proteins are given in kilodaltons to the left of each gel; $\mathrm{m}$, protein size marker. Both gels are Coomassie stained. (a) SDS-PAGE analysis of affinity purified proteins. (b) Non-denaturing SDS-PAGE analysis of Knob and GFP-Knob. Arrows point to trimers. 
also modified the C-terminal globular domain of the Ad5 Knob, which binds with high affinity to ubiquitous cellular receptors known as Coxsackievirus adenovirus receptors (CAR) (2). We expressed both peptides alone and as GFPtagged versions (GFP-eHRG and GFP-Knob) in bacteria. All proteins were produced at high levels, were high- ly soluble and could be isolated to a high degree of purity by affinity chromatography. Figure 1a shows that these proteins migrate at their expected molecular weights under denaturing conditions.

The homotrimeric nature of the Knob protein has been well established (15, 33). To assess whether the GFP moiety affects Knob trimer assembly, we deter- mined the molecular size of both GFPtagged and untagged versions of the Knob (GFP-Knob and Knob, respectively) under native conditions. Using nondenaturing SDS-PAGE (23), we found that both Knob and GFP-Knob migrate at the expected size for trimers (Figure 1b), suggesting that the GFP segment does not interfere with oligomerization.

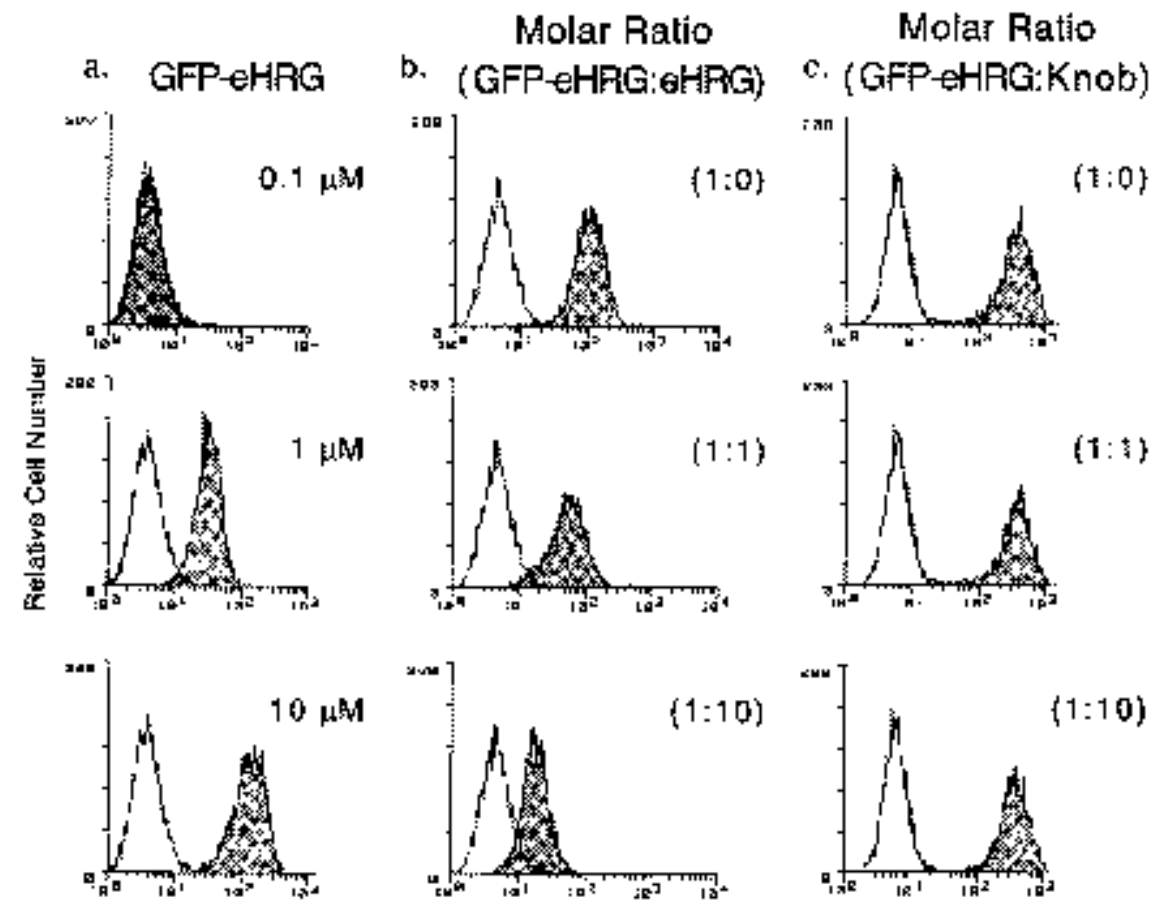

Flęorescence Intensity Fludrescence Intensity Fledrescence Intẹnsity

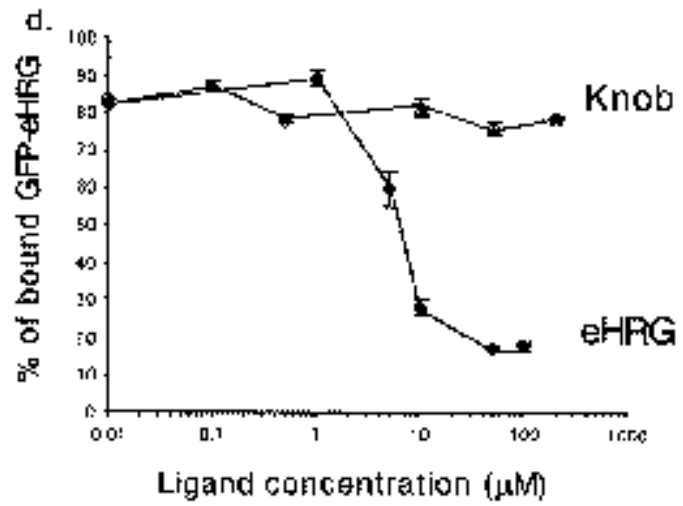

Figure 2. FACS results of cell-binding assays on MDA-MB-453 cells. Untreated cells are shown in white. Treated cells are shown in gray. Fluorescence intensity is shown on the $\mathrm{x}$-axis using a logarithmic scale. (a) Dose-related fluorescence enhancement by the indicated concentrations of cell-bound GFP-eHRG. (b and c) Competition assays. Cells were incubated with GFP-eHRG in the presence of varying concentrations of non-GFP-tagged ligands: (b) eHRG or (c) Knob. (d) Summary of competition assays. The value of the mean population shift of cells treated with GFP-eHRG alone was set at 100\%, indicating total bound protein. The values of the mean population shifts produced by the addition of eHRG (diamonds) or Knob (squares) were converted to a percentage of the total bound GFP-eHRG and plotted against the concentrations of each competitor. 


\section{GFP-Ligand Fusions Retain Receptor-Binding Activity}

The human breast cancer cell line MDA-MB-453, which overexpresses HER2-containing receptors, was used to test receptor binding of GFP-eHRG. Increasing concentrations of GFPeHRG were incubated with MDA-MB453 cells on ice in the presence of a blocking agent (3\% milk powder) to re- duce nonspecific binding. Cells were washed thoroughly to remove nonspecifically bound protein and analyzed by FACS. GFP-eHRG exhibits dosedependent binding activity, as shown by a progressive increase in fluorescence shift of the treated populations of cells (Figure 2a).

We repeated the cell-binding assays in the presence of increasing amounts of untagged competitor (eHRG) to

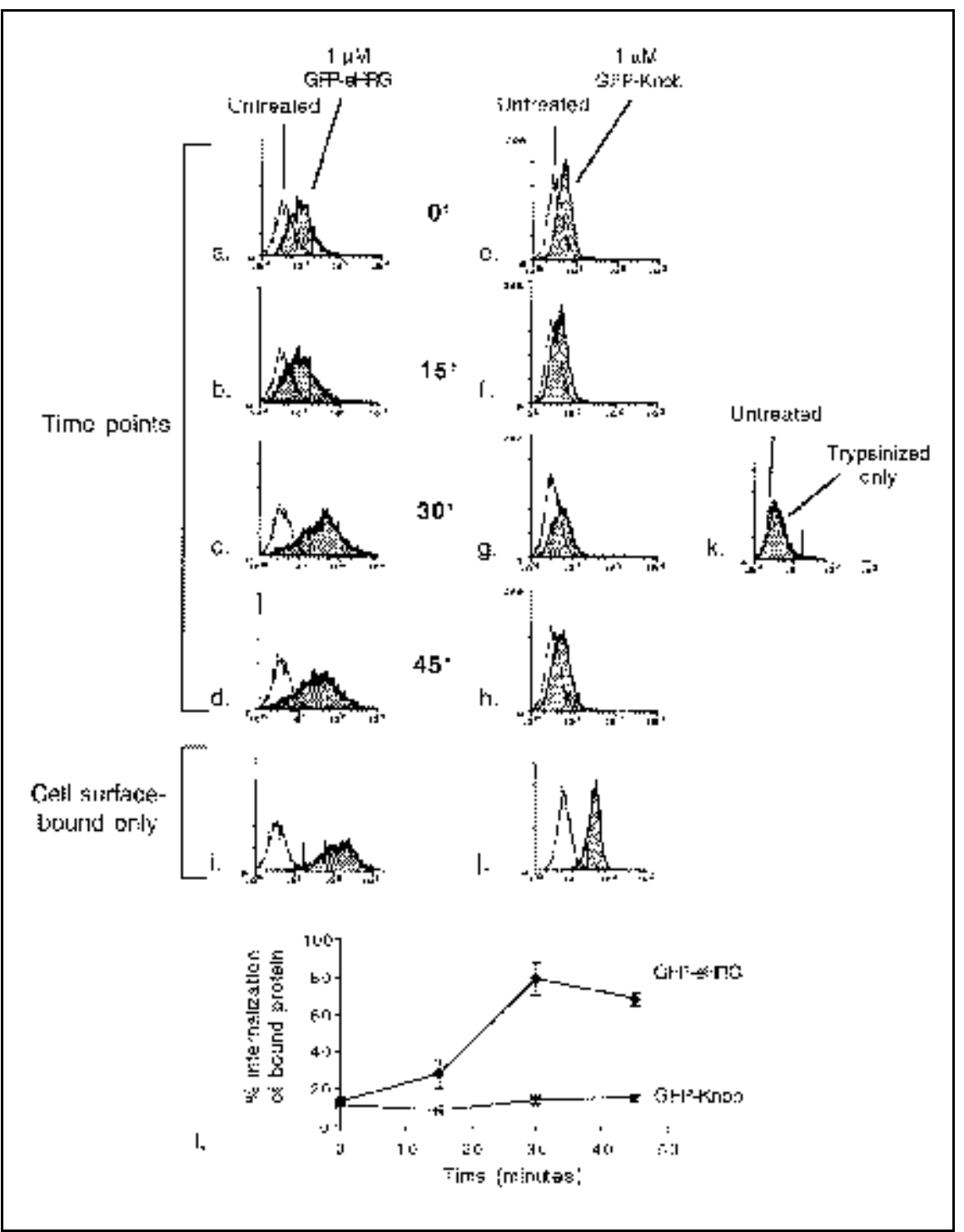

Figure 3. FACS results of internalization assay. Untreated MDA-MB-453 cells are shown in white. Treated MDA-MB-453 cells are shown in gray. $(\mathrm{a}-\mathrm{d}$ and $\mathrm{e}-\mathrm{h}$ ) Fluorescence shift of the GFP-ligand treated cells collected at the indicated time points after warming. ( $i$ and $j$ ) Fluorescence shift of untrypsinized cells treated with the indicated GFP-ligands. (k) Untreated cells (white) and untreated trypsinized cells (gray). In k, the curves superimpose, showing that trypsin treatment alone does not produce an artifactual fluorescence shift. (1) Summary of internalization assay. The value of the mean population shift produced by the indicated GFP-ligand on untrypsinized cells ( $i$ and $j$ ) was set at $100 \%$, indicating total bound protein. The values of the mean population shifts produced by the treated cells at each time point (a-d and $\mathrm{e}-\mathrm{h}$ ) were converted to a percentage of the total bound protein on untrypsinized cells. 
determine whether the observed fluorescence shift is a result of specific ligand binding to cellular receptors and not caused by nonspecific binding to cell surfaces. The fluorescence shift resulting from GFP-eHRG binding is sequentially reduced in the presence of successively increasing concentrations of non-GFP-tagged eHRG (Figure 2b). To further confirm receptor-binding specificity, we tried to compete away GFP-eHRG binding with an unrelated protein (Knob). The fluorescence shift resulting from GFP-eHRG binding could not be reduced with excess concentrations of the unrelated competitor and so established the specificity of this cell-binding assay (Figure 2c).

Figure $2 \mathrm{~d}$ summarizes the results of these competition assays and shows that the amount of bound GFP-ligand that is competed away inversely correlates with the concentration of untagged competitor. Similar results were obtained using GFP-Knob and Knob protein on HeLa cells. Thus, the GFP-

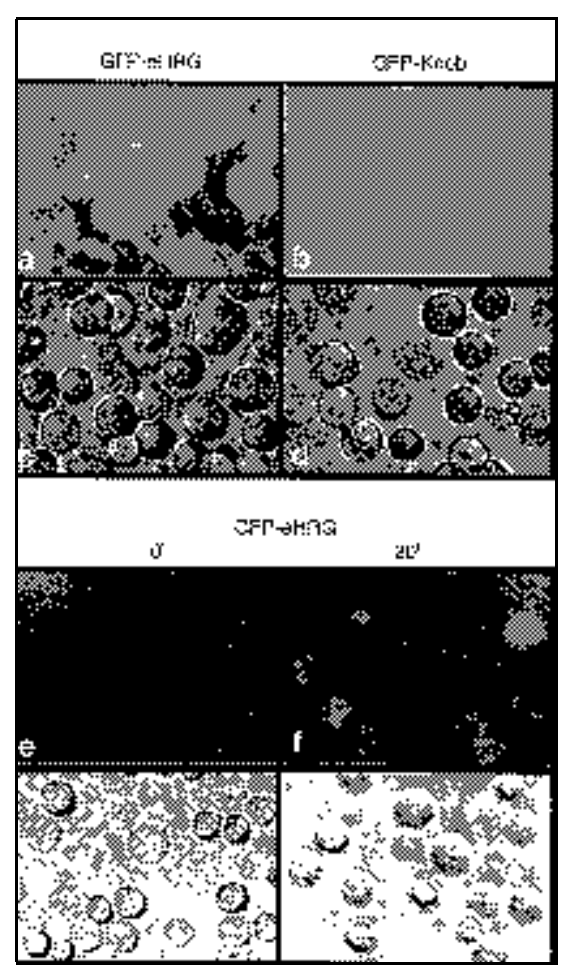

Figure 4. Fluorescence microscopy of MDA MB-453 cells from internalization assay at 40 $\times$ magnification under fluorescent light $(a$, $b, e$ and $f)$ and regular light (c, $d, g$ and $h$ ). (a-d) View of untrypsinized cells at $30 \mathrm{~min}$ after warming. $(\mathrm{e}-\mathrm{h})$ View of trypsinized cells at 0 min (e and g) and $30 \mathrm{~min}$ ( $\mathrm{f}$ and h) after warming. tagged ligands retain specific binding to their respective receptor targets, indicating that the GFP-moiety does not interfere with the receptor-binding function.

\section{Establishing a FACS-Based Assay for Internalization Activity}

We modified the cell-binding assay to measure intracellular accumulation of the GFP-tagged proteins to determine whether the heregulin receptor internalizes after binding and, if so, its rate of internalization. First, we allowed MDA-MB-453 human breast cancer cells to bind GFP-eHRG on ice and washed the cells extensively to remove unbound proteins. The cells were then incubated at $37^{\circ} \mathrm{C}$ and collected at sequential time points after warming. Each cell harvest was immediately followed by treatment with trypsin/EDTA to remove residual cell surface-bound proteins and then analyzed by FACS. Internalized GFP is protected from trypsinization and so produces a fluorescence shift that is detectable by FACS. This assay approach predicts that a progressively increased accumulation of intracellular GFP should produce a progressively enhanced fluorescence shift in the treated cell population over time. In contrast, GFP-ligands continuously retained on the cell surface are removed by trypsin treatment and produce no fluorescence signal at any time point.

As shown in Figure 3, a-d, MDAMB-453 cells treated with GFP-eHRG exhibit an increase in fluorescence shift over time, suggesting the accumulation of internalized GFP-eHRG. To verify our findings, we performed the same assay using GFP-Knob. It has previously been shown that the Knob receptor, CAR, binds the Knob with high affinity but does not internalize after ligand binding (32). We did not expect GFPKnob to produce an increase in fluorescence shift over time because of its inability to internalize. Indeed, no such shift in fluorescence is produced when cells are treated with GFP-Knob (Figure 3 , e-h), despite the high degree of binding on the surface of untrypsinized but thoroughly washed MDA-MB-453 cells (Figure 3j). Trypsinization of cells alone does not induce a fluorescence shift (Figure 3k). Figure 31 summarizes these findings and shows that of the total GFP-eHRG bound on the surface of MDA-MG-453 cells at $0 \mathrm{~min}, 80 \%$ is internalized by $30 \mathrm{~min}$ at $37^{\circ} \mathrm{C}$, suggesting rapid internalization after binding.

Microscopic examination of our treated cells shows a clear difference in distribution of GFP-eHRG and GFPKnob after performing the internalization assay. At 30 min after warming but before trypsinization, there are bright, punctate fluorescent foci resembling endosome-like compartments in the cells treated with GFP-eHRG (Figure 4a). This contrasts with the diffuse fluorescence observed on cells treated with GFP-Knob (Figure 4b). Under regular light, both sets of treated cells appear morphologically similar (Figure 4, c and d) and unchanged from the morphology of healthy, untreated MDA-MB-453 cells. A clear difference in fluorescence also emerges from trypsinized MDAMB-453 cells at 0 and $30 \mathrm{~min}$ after warming. Although little fluorescence above background is apparent at $0 \mathrm{~min}$ (Figure 4e), many bright intracellular foci are seen at $30 \mathrm{~min}$ (Figure 4f). This pattern clearly shows that many GFPeHRG proteins have become internalized by $30 \mathrm{~min}$ and so are protected from trypsin treatment.

It may be feasible to apply the methods presented here to a broader range of applications when testing ligand-receptor activity. For example, FACS may use GFP-tagged ligands in place of antibodies to identify and sort cells. Our assays may also be used to compare the binding and internalization of different ligand or receptor isomers or mutants. In addition, our approach may simplify the analysis of different structural mutations on receptor binding and internalization. The stability of GFP as a fusion protein allows a number of different applications for the study of ligand-receptor interactions under natural conditions and avoids the need to fix cells at a certain endpoint or treat biological samples with radioactive reagents.

\section{ACKNOWLEDGMENTS}

We thank Nori Kasahara for providing the heregulin sequence and breast cancer cell lines. We are also grateful to the following people for ongoing 
discussions and support: Xinhua Chen, Gene Chung, John Daoud, Yasuo Ham amori, John Hwang, Tatsuya Iso, Kimi Kong, Jochen Muller-Ehmsen, Alex Oxyzoglou, Coralie Poizat, Tsuyoshi Sakoda, Vittorio Sartorelli, David Tinsley and Hung-Yi Wu. This work was supported by grants to L.H.K. from the Susan G. Komen Breast Cancer foundation and the Department of Defense; a fellowship to L.K.M.-K. from the National Institutes of Health grant no. HL09638-02 supported this work.

\section{REFERENCES}

1.Bacus, S.S., C.R. Zelnick, G. Plowman and Y. Yarden. 1994. Expression of the erbB-2 family of growth factor receptors and their ligands in breast cancers. Implication for tumor biology and clinical behavior. Am. J. Clin. Pathol. 102:S13-S24.

2.Bergelson, J.M., J.A. Cunningham, G. Droguett, E.A. Kurt-Jones, A. Krithivas, J.S. Hong, M. S. Horwitz, R.L. Crowell and R.W. Finberg. 1997. Isolation of a common receptor for Coxsackie B viruses and adenoviruses 2 and 5. Science 275:1320-1323.

3.Carraway, K.L., III and L.C. Cantley. 1994. A neu acquaintance for erbB3 and erbB4: a role for receptor heterodimerization in growth signaling. Cell 78:5-8.

4.Carraway, K.L., III, M.X. Sliwkowski, R. Akita, J.V. Platko, P.M. Guy, A. Nuijens, A.J. Diamonti, R.L. Vandlen et al. 1994. The erbB3 gene product is a receptor for heregulin. J. Biol. Chem. 269:14303-14306.

5.Carraway, K.L, III and R.A. Cerione. 1993. Fluorescent-labeled growth factor molecules serve as probes for receptor binding and endocytosis. Biochemistry 32:12039-12045.

6.Chalfie, M. 1995. Green fluorescent protein. Photochem. Photobiol. 62:651-656.

7.Chalfie, M., Y. Tu, G. Euskirchen, W.W. Ward and D.C. Prasher. 1994. Green fluorescent protein as a marker for gene expression. Science 263:802-805.

8.Crameri, A., E.A. Whitehorn, E. Tate, and W.P. Stemmer. 1996. Improved green fluorescent protein by molecular evolution using DNA shuffling. Nat. Biotechnol. 14:315-319.

9.Delagrave, S., R. E. Hawtin, C.M. Silva, M.M. Yang and D.C. Youvan. 1995. Redshifted excitation mutants of the green fluorescent protein. BioTechnology 13:151-154.

10.Elliott, G. and P. O'Hare. 1997. Intercellular trafficking and protein delivery by a herpes virus structural protein. Cell 88:223-233.

11.Epel, B.L., H.S. Padgett, M. Heinlein and R.N. Beachy. 1996. Plant virus movement protein dynamics probed with a GFP-protein fusion. Gene 173:75-79.

12.Goldman, R., R.B. Levy, E. Peles and Y. Yarden. 1990. Heterodimerization of the erbB-1 and erbB-2 receptors in human breast carcinoma cells: a mechanism for receptor transregulation. Biochemistry 29:1102411028 .
13.Han, X., N. Kasahara and Y.W. Kan. 1995 Ligand-directed retroviral targeting of human breast cancer cells. Proc. Natl. Acad. Sci. USA 92:9747-9751.

14.Harris, A., M. Adler, J. Brink, R. Lin, M. Foehr, M. Ferrer, B.C. Langton-Webster, R.N. Harkins and S.A. Thompson. 1998. Homologue scanning mutagenesis of heregulin reveals receptor specific binding epitopes. Biochem. Biophys. Res. Commun. 251:220224.

15.Henry, L.J., D. Xia, M.E. Wilke, J. Deisenhofer and R.D. Gerard. 1994. Characterization of the knob domain of the adenovirus type 5 fiber protein expressed in Escherichia coli. J. Virol. 68:5239-5246.

16.Holmes, W.E., M.X. Sliwkowski, R.W. Akita, W.J. Henzel, J. Lee, J.W. Park, D. Yansura, N. Abadi et al. 1992. Identification of heregulin, a specific activator of p185erbB2. Science 256:1205-1210.

17.Hung, M.C., A. Matin, Y. Zhang, X. Xing, F. Sorgi, L. Huang and D. Yu. 1995. HER$2 /$ neu-targeting gene therapy - a review. Gene 159:65-71.

18.Katz, B.Z., D. Krylov, S. Aota, M. Olive, C. Vinson and K.M. Yamada. 1998. Green fluorescent protein labeling of cytoskeletal structures-novel targeting approach based on leucine zippers. BioTechniques 25:298-304.

19.Lenferink, A.E., R. Pinkas-Kramarski, M.L. van de Poll, M.J. van Vugt, L.N. Klapper, E. Tzahar, H. Waterman, M. Sela et al. 1998. Differential endocytic routing of homoand hetero-dimeric ErbB tyrosine kinases confers signaling superiority to receptor heterodimers. EMBO J. 17:3385-3397.

20.Levkowitz, G., H. Waterman, E. Zamir, Z. Kam, S. Oved, W.Y. Langdon, L. Beguinot, B. Geiger and Y. Yarden. 1998. c-Cbl/Sli-1 regulates endocytic sorting and ubiquitination of the epidermal growth factor receptor. Genes Dev. 12:3663-3374.

21.Li, W., J.W. Park, A. Nuijens, M.X. Sliwkowski and G.A. Keller. 1996. Heregulin is rapidly translocated to the nucleus and its transport is correlated with c-myc induction in breast cancer cells. Oncogene 12:2473-2477.

22.Moores, S.L., J.H. Sabry and J.A. Spudich. 1996. Myosin dynamics in live Dictyostelium cells. Proc. Natl Acad. Sci. USA 93:443-446.

23. Novelli, A. and P.A. Boulanger. 1991. Assembly of adenovirus type 2 fiber synthesized in cell-free translation system. J. Biol. Chem. 266:9299-9303.

24.Prasher, D.C., V.K. Eckenrode, W.W. Ward, F.G. Prendergast and M.J. Cormier. 1992. Primary structure of the Aequorea victoria green-fluorescent protein. Gene 111:229-233.

25.Press, M.F., L.A. Jones, W. Godolphin, C.L. Edwards and D.J. Slamon. 1990. HER2/neu oncogene amplification and expression in breast and ovarian cancers. Prog. Clin. Biol. Res. 354A:209-221.

26.Slamon, D.J. and G.M. Clark. 1988. Amplification of c-erbB-2 and aggressive human breast tumors? Science 240:1795-1798.

27.Slamon, D.J., G.M. Clark, S.G. Wong, W.J. Levin, A. Ullrich and W.L. McGuire. 1987. Human breast cancer: correlation of relapse and survival with amplification of the HER2/neu oncogene. Science 235:177-182.
28.Sliwkowski, M.X., G. Schaefer, R.W. Akita, J.A. Lofgren, V.D. Fitzpatrick, A. Nuijens, B.M. Fendly, R.A. Cerione et al. 1994. Coexpression of erbB2 and erbB3 proteins reconstitutes a high affinity receptor for heregulin. J. Biol. Chem. 269:14661-14665.

29.Stearns, T. 1995. Green fluorescent protein. The green revolution. Curr. Biol. 5:262-264.

30.Tzahar, E., G. Levkowitz, D. Karunagaran, L. Yi, E. Peles, S. Lavi, D. Chang, N. Liu et al. 1994. ErbB-3 and ErbB-4 function as the respective low and high affinity receptors of all Neu differentiation factor/heregulin isoforms. J. Biol. Chem. 269:25226-25233.

31. Waterman, H., I. Sabanai, B. Geiger and Y. Yarden. 1998. Alternative intracellular routing of ErbB receptors may determine signaling potency. J. Biol. Chem. 273:13819-13827.

32.Wickham, T.J., P. Mathias, D.A. Cheresh and G.R. Nemerow. 1993. Integrins $\alpha_{\mathrm{v}} \beta_{3}$ and $\alpha_{\mathrm{v}} \beta_{5}$ promote adenovirus internalization but not virus attachment. Cell 73:309-319.

33.Xia, D., L.J. Henry, R.D. Gerard and J. Deisenhofer. 1994. Crystal structure of the receptor-binding domain of adenovirus type 5 fiber protein at $1.7 \mathrm{~A}$ resolution. Structure 2:1259-1270.

34. Yang, F., L.G. Moss and G.N. Phillips, Jr. 1996. The molecular structure of green fluorescent protein. Nat. Biotechnol. 14:12461251.

35. Yarden, Y. and R.A. Weinberg. 1989. Experimental approaches to hypothetical hormones: detection of a candidate ligand of the neu protooncogene. Proc. Natl. Acad. Sci. USA 86:3179-3183.

Received 2 November 1999; accepted 25 April 2000.

Address correspondence to:

Dr. Larry Kedes

Institute for Genetic Medicine and

Department of Biochemistry \&

Molecular Biology

University of Southern California

Keck School of Medicine

2250 Alcazar Street CSC240

Los Angeles, CA 90033, USA

e-mail:kedes@hsc.usc.edu 